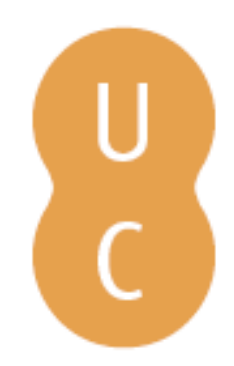

\title{
pommalina
}

\section{Roteiros bíblicos de Fedra}

Autor(es): $\quad$ Ramos, José Augusto M.

Publicado por: Centro de Estudos Clássicos e Humanísticos da Universidade de

URL

persistente: URI:http://hdl.handle.net/10316.2/30109

$\begin{array}{ll}\text { DOI: } & \text { DOI:http://dx.doi.org/10.14195/978-989-721-010-5_6; DOI:978-989-721- } \\ \text { 010-5 (PDF) }\end{array}$

Accessed : $\quad$ 26-Apr-2023 08:01:58

A navegação consulta e descarregamento dos títulos inseridos nas Bibliotecas Digitais UC Digitalis, UC Pombalina e UC Impactum, pressupõem a aceitação plena e sem reservas dos Termos e Condições de Uso destas Bibliotecas Digitais, disponíveis em https://digitalis.uc.pt/pt-pt/termos.

Conforme exposto nos referidos Termos e Condições de Uso, o descarregamento de títulos de acesso restrito requer uma licença válida de autorização devendo o utilizador aceder ao(s) documento(s) a partir de um endereço de IP da instituição detentora da supramencionada licença.

Ao utilizador é apenas permitido o descarregamento para uso pessoal, pelo que o emprego do(s) título(s) descarregado(s) para outro fim, designadamente comercial, carece de autorização do respetivo autor ou editor da obra.

Na medida em que todas as obras da UC Digitalis se encontram protegidas pelo Código do Direito de Autor e Direitos Conexos e demais legislação aplicável, toda a cópia, parcial ou total, deste documento, nos casos em que é legalmente admitida, deverá conter ou fazer-se acompanhar por este aviso.

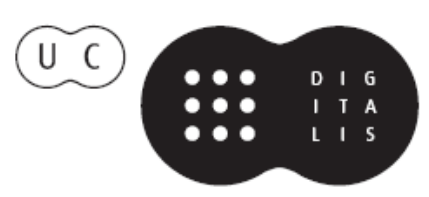




\section{Hipólito e Fedra}

\section{nos caminhos de um mito}

Carlos A. Martins de Jesus, Claudio Castro Filho, José Ribeiro Ferreira (coords.) 


\section{RoteIros bíbLICOS DE FEDRA}

José Augusto M. Ramos

Universidade de Lisboa

Para compor uma geografia teatral com a imagem de Fedra, as tradições culturais da Grécia foram entretecendo caminhos e cruzando figuras. Foram, desta maneira, colocando em jogo os mais variados circuitos do relacionamento emocional e familiar. $\mathrm{Na}$ densidade desse espaço, ocorrem universalmente alguns relacionamentos que são construtivos e benfazejos, mas aparecem também alguns elementos bem nefastos. Estes últimos fazem com que as aventuras do amor exponham momentos menos felizes, podendo mesmo atingir laivos incontornáveis de tragédia. A variedade e intensidade dos temas humanos que marcam a tragédia de Fedra ocorrem igualmente na Bíblia. O seu tratamento, contudo, decorre ali em perspetivas diferentes.

A consideração destes percursos, de evidente ressonância existencial, pode ser útil como espelho humano de uma cultura que é diferente da dos Gregos, mas pode ser coincidente com a destes em muitos dos seus dados. Por isso nos parece útil focar algumas paisagens situadas em diversos roteiros e temas da Bíblia, nos quais se podem entrever linhas de convergência com os de Fedra. Sob formas de maior ou menor analogia, também os traços vivenviais de Fedra por ali se difundem, de forma mais ou menos carregada.

Com o interesse da utilidade direta, a biografia grega de Fedra vai definindo e acumulando na personagem os traços psicossociais que, na sua cultura, soavam mais pertinentes. Pressupomos o seu teor concreto por detrás das imagens de comparação que recolhemos na literatura bíblica. Julgamos, por isso, desnecessário recolher aqui qualquer resumo sobre os passos gregos da história de Fedra. Procuraremos respigar alguns temas que sugerem correspondências com os traços da narrativa, sem nos delimitarmos aos tópicos mais destacados na tragédia euripidiana.

\section{O pólo familiar na aventura social do amor}

Que as vicissitudes e decisões sobre o destino amoroso de uma mulher possam ter particular ressonância no seio da sua família, como unidade orgânica, é também uma condição humana normal, segundo a mentalidade do homem do mundo pré-clássico e bíblico. Esse lado familiar orgânico pode motivar, mesmo sem que o pai esteja morto ou ausente, que o destino amoroso de uma mulher se veja sujeito a interferências dramáticas por parte dos seus irmãos.

A este propósito, o episódio bíblico mais marcante e exemplar pode ser o de Dina, filha de Jacob (Gn 34, 1-31). Esta foi primeiro raptada e violentada 
por um cananeu, mas, logo de seguida, passou a ser amada e foi solicitada em casamento. $\mathrm{O}$ violador que assim se transformou em amante apaixonado era Siquém, filho de Hamor, chefe político de um grupo de cananeus na região central da Palestina. A negociação foi conduzida perante o pai, Jacob, mas estavam igualmente presentes os seus outros filhos, a modo de assembleia familiar.

Jacob parecia estar a negociar de boa fé, percebendo e aceitando que com aquele casamento se pudesse estar a dar início a uma nova fase política de convivência entre os dois grupos. A narrativa historiográfica como que validava aquele entendimento, vendo nele uma via de futuro. Os irmãos de Dina, contudo, mantiveram, desde o princípio, uma atitude vingativa de modo camuflado. Não aceitavam ultrapassar a desonra que tinham experimentado, por causa da violação da irmã por parte de um daqueles estrangeiros. Os homens de Siquém tinham concordado, de boa fé, em se sujeitar a fazer a circuncisão, de modo a poderem entrar em aliança com os hebreus.

Estes, porém, aproveitaram-se do estado de fraqueza provocado pela circuncisão e mataram à espada todos os homens de Siquém. O lado positivo do desenvolvimento do amor, depois da violação, não evitou a guerra entre as duas sociedades. Foi uma tragédia derivada de intervenções contraditórias no decurso da história.

É de sublinhar, entretanto, o facto de o pai, Jacob, ter assumido em toda esta ocorrência um papel muito menos decisivo do que aquele que é desempenhado pelos irmãos de Dina. O decisivo carrega a marca do trágico. E são os irmãos que dão esse passo.

Se eventualmente a circunstância em que o irmão de Fedra a deu em casamento a Teseu estiver em ligação com algum dos múltiplos negócios motivados pela diplomacia real, então ele estaria a comportar-se como o novo rei de Creta, tratando dos seus negócios políticos com Teseu de Atenas. Muitos casamentos de iniciativa real e de interesse político obedeciam, na Antiguidade, a este padrão. A história do Antigo Oriente conhece estes processos. Na Bíblia, são menos frequentes estes negócios diplomáticos e não são práticas muito bem vistas. A figura da fenícia Jezabel, com quem o rei Acab casou, é um exemplo (1Rs 16,30-34). Esta linguagem diplomática dos casamentos políticos aparece quase caricaturada a propósito da prática de Salomão, também para ele com consequências pouco brilhantes (1Rs 11,1-13).

No genérico destas histórias institucionais não costuma sobrar espaço para espelhar o lado humano das mulheres diretamente envolvidas no negócio, se bem que, por vezes, se detetem atitudes de proteção que deixam perceber essas situações de mal-estar pessoal como plausíveis de acontecer ${ }^{1}$. Quem sabe se

\footnotetext{
${ }^{1}$ Talvez por algum sentimento de superioridade, os egípcios mostravam relutância em
} 
esta circunstância não poderia justificar também uma parte da insegurança que a relação entre Fedra e Teseu parece ter chegado a conhecer. A conveniência política não coincide sempre com o sentido da experiência pessoal e esta pode representar, por vezes, logros gritantes.

Idilicamente, uma das cantigas do Cântico dos Cânticos apresenta como preocupação afetuosa de uns irmãos a de saber qual o papel que lhes caberia assumir relativamente ao futuro amoroso de uma sua irmã ainda pequena:

Temos uma irmã pequena, a qual ainda não tem seios.

Que faremos pela nossa irmã, quando vierem falar nela?

Se ela é uma muralha, nela faremos ameias de prata; se é uma porta, reforçá-la-emos com traves de cedro.

A vivência familiar do tema helénico de Fedra poderá não ter este teor irénico. Mas a situação é igualmente cúmplice do ponto de vista familiar: e não será esta a única vez que se podem descobrir sentidos diferentes entre temas gregos e bíblicos, mesmo quando parecem ser materialmente coincidentes.

\section{Cumplicidades e conflitos domésticos do amor}

Podem verificar-se casos em que um homem se dispõe a aceitar que a sua mulher possa camuflar a sua condição de casada, aceitando a eventualidade de vir a ser mulher de outro, normalmente mais poderoso, sem se ver nisso dramas de maior. A implicação entre amor e exclusividade sexual podia assim consentir exceções tranquilas. Verifica-se que este tópico conhecia algum eco social. Por isso, dava azo a histórias que conheceram evidente atrativo literário. É por esse interesse que uma história deste género aparece mais do que uma vez na Bíblia. Ela acontece com Abraão (Gn 12, 10-20) e, depois, com Isaac (Gn 26,8-11). Ora, esta cedência não parece implicar nenhum menosprezo pela própria mulher. A situação é, pelo contrário, considerada como um mal menor e pode ser consentida e reconhecida como benfazeja para o interesse de ambos os cônjuges. Até os de fora, os "inimigos", acabam por assumir, relativamente a estes casos e sem hesitar, uma posição justa (Gn 26,10), que até os interessados parecem sublinhar com agrado.

permitir que as suas princesas fossem dadas em casamento político para o estrangeiro. Aquilo que é referido a propósito de Salomão $(1 \mathrm{Rs} 9,16 ; 11,1)$ deve ser um caso atípico na política faraónica. 
O facto, porém, não é tratado como uma vivência com tonalidades de drama nem como uma ação moralmente reprovável. As perplexidades características da consciência trágica ficaram afastadas. A transcendência do ato como que ficou abafada. O facto de Sara ser meia irmã de Abraão não impede que o seu casamento com ela seja visto com toda a naturalidade (Gn 20,12). Os fatores que definem o conceito de incesto podem ser, por conseguinte, variáveis.

Sendo aparentemente menos chocante, o caso de Rúben que teve relações com uma concubina do seu pai, Jacob, é objeto de uma degradação com a recusa do direito de primogenitura que lhe competia, por ter aviltado a honra do leito paterno ( $\mathrm{Gn} 35,22$ e 49,3-4). Uma concubina era, de facto, uma das "esposas". Os direitos paternos serão igualmente uma realidade que um filho não deve infringir, à semelhança daquilo que acontece com o reconhecimento dos direitos políticos de um rei, quando se considera inadequado apoderar-se de uma sua concubina ( $2 \mathrm{Sm} \mathrm{3,6-11).} \mathrm{No} \mathrm{caso}$ citado, a acusação aparentemente infundada de ter cometido este "crime" leva Abner, antes aliado, a passar do campo político de Saul para o espaço dos apoiantes do seu adversário David.

Certo dia, Lot encontrou-se numa situação de perplexidade familiar particularmente difícil, ao considerar preferível que os sodomitas violassem as suas filhas, quando eram ainda virgens, como maneira de impedir que eles sodomizassem os hóspedes que pouco antes tinha acolhido em sua casa. $\mathrm{O}$ critério ético que ele tomava em consideração era que a lei da hospitalidade deveria prevalecer sobre o conforto da vivência sexual das próprias filhas $(\mathrm{G} n$ 19, 4-8). Para nós é algo estranho que Lot estivesse assim disposto a sacrificar esse valor e bem-estar pessoal, para se mostrar devidamente hospitaleiro.

Do conjunto de referências e normas sobre o tema do incesto, na Bíblia (Gn 49, 3-4), parece avultar a impressão de que a dimensão ponderada é a de reconhecer que a pessoa eventualmente afetada pelo ato incestuoso é detentora de direitos que devem prevalecer. Estamos perante uma hierarquia de valores, em que os direitos de um dos membros da família são prioritários. $\mathrm{O}$ incesto é mais um caso de conflito na hierarquia familiar dos direitos do que uma questão de indecência moral propriamente dita. Indecência sexual com quebra de respeito pela identidade do pai parece ser o que é considerado reprovável e digno de castigo e maldição da parte de Noé para com um dos seus filhos, que viu casualmente a nudez do pai e não foi discreto ( $\mathrm{Gn} 9,20-27)$. O incesto é um pecado familiar.

É provável que um dos casos mais prováveis de incesto seja o das filhas de Lot que embriagaram o seu pai e tiveram relações sexuais com ele, de modo a que cada uma delas conseguisse sucessivamente engravidar e garantir descendência (Gn 19, 30-38). A história é narrada como uma simples explicação da origem de dois grupos étnicos. O nome de Moab soa, em etimologia popular, como 
significando aquele que é "do pai" e Ben-Ami significaria "filho da minha parentela" (Gn 19,36-38). O nome que se lhes atribui pode representar uma marca com algo de anormal.

Os casos de incesto fazem naturalmente parte das listas de desregramentos morais apresentados como sinal da degradação atingida pelos hebreus (Ez 22,10-11).

A literatura assinala realmente a existência de conflitos passionais entre pais e filhos e regista esse facto como um foco de perplexidades. A própria coincidência amorosa entre um pai e um filho, em virtude do qual a vida amorosa de um e de outro se sobrepõe e contrapõe, é vista como algo indevido e pouco humano. É como o facto de pai e filho frequentarem a mesma concubina (Dt 18,17). A inibição não tem propriamente a ver com conotações de poligamia. Esta nem sequer parece constituir uma preocupação especial naquela época. São incompatibilidades diretas e quase semânticas na coincidência entre o espaço amoroso do pai e o do filho. Nota-se que o núcleo da incompatibilidade se situava no espaço imaginário da intimidade interparental. Descobrir a nudez parental parece exibir incompatibilidades indiscutíveis (Dt 18 e 20). A incompatibilidade semântica conota uma realidade sem sentido. É como que um absurdo antropológico.

Aparecem, por vezes, esboçadas razões específicas para se proibir a partilha amorosa entre parentes próximos, tal como quando se proíbe ter relações sexuais com uma mulher e com a irmã desta, porque isso provocaria rivalidades (Lv 18, 18). Esta referência psicologizante parece uma curiosidade fácil e um truísmo desnecessário. As perplexidades verdadeiramente motivadoras situavam-se intuitiva e esteticamente a um nível mais profundo. Estes circuitos eram enoveladores e não construtivos.

Para além deste aspeto ominoso da partilha da mesma vida amorosa entre con-familiares, a ousadia de um pretendente ao trono se apoderar das concubinas do pai, parece ser visto sobretudo no seu significado político, como modo estratégico de assumir o poder com todos os seus instrumentos e semânticas e com todas as suas demonstrações. A conflituosidade de teor amoroso e a confrontação de âmbito familiar não ficam, de qualquer modo, excluídas desta complexidade de significados e de jogos em que a vida afetiva, a vida familiar e a vida política se entrechocam.

O caso provocado por Amnon, filho de David, que procurou, por meio de estratagemas, satisfazer a paixão que sentia por uma sua meia irmã, de nome Tamar, não é reprovado pelo facto de esta ser sua meia irmã. Uma das hipóteses de solução ali aventadas foi até a de pedirem ao rei, provavelmente na qualidade de pai da jovem e não como autoridade política legitimadora, que a desse em casamento ao seu meio irmão, Amnon. Aquilo que era considerado indevido e ignominioso em Israel era o facto de ela ser por ele violentada, 
sendo familiar e ainda virgem (2Sm 13, 1-22). O nível social de ambos marca decisivamente o significado destes acontecimentos.

Nos códigos legais de Israel, encontramos sínteses importantes de leis a proibir o relacionamento sexual de um israelita com diversas categorias de mulheres envolvidas por laços de parentesco, tais como a mãe, qualquer mulher do próprio pai, uma irmã, uma neta, uma filha da mulher do pai, uma irmã do pai ou da mãe, uma tia, uma nora, uma cunhada ( $\operatorname{Lv} 18,6-16)$, ou a sogra (Dt 27, 23).

Como castigo do incesto anuncia-se a esterilidade ( $\operatorname{Lv} 20,21)$, que pode ser apenas enunciada como definição de falta de mérito, mais do que da vontade de a provocar eventualmente. Particularmente duro parece ser o castigo de condenar à morte pelo fogo um homem que assume maritalmente uma mulher junto com uma filha da mesma $(\operatorname{Lv} 20,14)$, devendo os três serem condenados à fogueira.

Muito mais tarde e noutro contexto social, a relação sexual de um cristão de Corinto com a mulher do seu pai é castigada por Paulo com a expulsão da comunidade cristã $(1$ Cor $5,2.5)$.

\section{Um instituto familiar de solidariedade para viabilizar o amor}

Tal como acabamos de ver, o parentesco de linha vertical (filhos e netos e respetivas afinidades, como sejam as noras e as sogras) bem como o parentesco de linha colateral (como irmãos, tios e sobrinhos) eram uma importante razão inibidora de casamento ou relacionamento sexual.

No entanto, um novo enquadramento social e jurídico, incidindo neste mesmo espaço de parentescos inibitórios, acaba por florescer uma verdadeira instituição bíblica para garantir viabilidade a casos de amor em risco. É a instituição do levirato².

Trata-se de um instituto legal, em que a grande proximidade familiar entre as pessoas, longe de constituir um óbice ao amor, aparece precisamente como o seu principal fator de viabilização. O papel solidário do novo marido é tão importante que a ideia do resgate passou a ser uma designação alternativa para a mesma fórmula de casamento numa endogamia estrita. É a instituição social do goel $^{3}$, alguém que, em razão do seu próximo parentesco, tem sobre si a obrigação de "resgatar" uma viúva de um seu parente, sobretudo se ela ficou viúva e sem filhos (Dt 25, 5).

${ }^{2} \mathrm{O}$ nome deste instituto jurídico deriva de "levir", que significa 'irmão do marido' (Dt 25,5-10).

${ }^{3} \mathrm{O}$ nome é o particípio ativo do verbo ga'al, que significa "resgatar". A viúva era entendida como ficando em condição de servidão. Desta semântica acabou por se originar o conceito de redentor, conceito que, nesta sua origem, não sublinhava nenhum matiz amartológico. A evolução futura da sua semântica haveria, entretanto, de se transformar, como é sabido. 
Para além de outros benefícios sociais procurados, este instituto funciona em benefício da mulher que fica viúva e sem filhos. Está em causa a sua proteção social. Mas uma intenção explícita é também a de suscitar descendência para o irmão falecido. Entre o benefício da mulher e o benefício do homem defunto, os interesses dividem-se; ou somam-se. O facto é que esta prática é de sentido único. Cria apenas a obrigação de solidariedade dos "cunhados" para com a sua parente que enviuvou.

Aliás, definir este interesse poderá ter provocado atitudes opostas. Não se conhece em profundidade o nível de aplicação histórica desta lei, mas também não se conhece uma grande história de recusa da mesma. $\mathrm{O}$ caso de recusa literariamente mais famoso é o de Onan que aceitou casar com a viúva do seu irmão, Er. Casou com ela, mas, depois, recusou-se a engravidar a mulher, com a justificação de que os filhos que iriam nascer não seriam dele mas do seu falecido irmão $(\mathrm{Gn} 38,9-10)^{4}$.

Contrariando, por conseguinte, as inibições de parentesco relativamente ao casamento e outros relacionamentos sexuais, este casamento de levirato aproveita precisamente algumas razões de parentesco para promover casamentos, transformando-o numa obrigação de solidariedade.

Um caso literário muito famoso de casamento baseado nesta regra de solidariedade familiar é aquele que preenche e justifica todo o romance histórico de Rute. Pela história contada, este casamento apresentava bases de plausibilidade muito precárias. $\mathrm{O}$ marido da viúva Rute não deixara parentes diretos e próximos (Rt 1, 7-13). Mesmo assim, a estrangeira Rute volta com a sogra, também viúva, para a pátria originária desta e o mérito da sua solidariedade (Rt 1, 16-22) virá a ser compensado com o aparecimento de um parente, disposto a cumprir o seu papel de redentor.

As deliciosas peripécias romanescas que levaram à conquista do seu novo marido e redentor (Rt 3,1-4-6) são a expressão de que esta história era envolvida de aceitação e suscitava alguma ternura e encanto. O elo final da história que faz de Rute uma das avós de David significa certamente uma grande aceitação por parte daqueles que ouviam e se reconheciam naquela história (Rt 4,22).

É também muito curioso o caso do casamento levirático de Judá e Tamar (Gn 38, 1-30). Casada primeiramente com Er, este morreu (Gn 38, 6-7). Casada, depois, com o cunhado, Onan, este evitava engravidá-la e morreu, segundo o texto, em consequência disso ( $\mathrm{Gn} 38,8-10)$.

Entretanto, o seu sogro, Judá, mandou a nora, Tamar, para casa do seu pai, enquanto esperava que o filho mais novo de Judá crescesse $(\mathrm{Gn} 38,11)$, para poder cumprir, por sua vez, a obrigação de levirato.

\footnotetext{
${ }^{4}$ É desta personagem que recebe nome a prática designada como onanismo.
} 
Descontente com o passar do tempo e temendo ainda que a morte dos dois irmãos pudesse levar o mais novo a hesitar em assumir a função levirática, Tamar, camuflando-se de prostituta de estrada, conseguiu engravidar do seu sogro, que entretanto também enviuvara. Assim conseguiu finalmente marido e descendência a dobrar, porque, desta vez, lhe nasceram dois gémeos ( $\mathrm{Gn}$ 38,12-30).

Todo o conjunto desta história respira encanto e finalmente sucesso e felicidade; o texto parece exprimir sentimentos de grande complacência com esta maneira de se escrever direito por linhas tortas. É uma história de muitas desgraças sem saída, mas nada trágica. E com esta instituição poderíamos estar exatamente no pólo oposto dos caminhos de Fedra. Em vez de tragédia, paira sobre os acontecimentos uma dose de paciência persistente. A solidariedade do levirato envolve esta história como uma imagem da providência, que é a lógica da história com as medidas do desejo.

\section{Impossibilidade de amar}

$\mathrm{O}$ amor é um espaço onde surgem naturalmente múltiplas aporias. $\mathrm{O}$ facto de ele se estruturar, como uma relação privilegiada e exigente, sobre a plataforma de consciência eu-tu introduz na sua performance todas as vicissitudes que a realidade dessa relação concita. Basta olhar para o discurso milenar que as vivências do amor suscitaram, desde as antigas líricas até às modernas canções, para tomar o pulso à gama de modulações que ele assume. Aceitações e recusas pontuam com intensidade o mapa e o calendário históricos do amor.

O ponto mais emblemático das aventuras de amor vividas por Fedra tem a ver com a impossibilidade de conquistar o enteado Hipólito: este acontecimento revoltou-a profundamente e acabou por definir um destino trágico para várias personagens da família. $\mathrm{Na}$ Bíblia, encontramos um episódio em boa parte equivalente a esta recusa de amar. José, já vendido para o Egito pelos seus próprios irmãos (outra cumplicidade de âmbito e ressonância familiar) é solicitado para uma aventura amorosa pela mulher do seu patrão, que o acolhera e lhe oferecera sobrevivência no Egito. José recusa a solicitação e provoca, por isso, a revolta e o ódio da sedutora. Dessa recusa e da consequente calúnia resulta um castigo para José (Gn 39,6-23). O seu castigo leva-o à prisão faraónica. Tal castigo é dramático, mas não é trágico. Pelo contrário, é construtivo e revela-se salvífico. A prisão foi a promessa e o caminho para a sua liberdade e suprema glória (Gn 41,1-57). O capítulo seguinte é, todo ele, de redenção, ascensão e apoteose de José como vice-rei do Egito. Aliás, a história de José está rotulada como uma história de sabedoria. Para além do moralmente modelar, leva a marca de um texto feliz. Nesta visão antropológica, os combates não são tragédia, são ações demiúrgicas de fundação da história como uma verdadeira ontologia do humano. O encontro 
com os irmãos, que ocorrerá em virtude da nova condição política de José, será o reatar da história para o povo hebreu, uma história que a fome de Canaã parecia vir a interromper dramaticamente.

Este tema tão especificamente valorizado na Bíblia é muito conhecido na literatura do Egito. Aqui, alguns matizes do drama são até mais coincidentes com o tema de Fedra. De facto, no conto dos Dois Irmãos ${ }^{5}$, a proposta amorosa tem caráter incestuoso, porque a mulher tenta seduzir um irmão do seu próprio marido e vê igualmente recusados os seus avanços. Também ali o tema aparece cultivado como um tema de sabedoria. Isto traduz uma maneira cultural específica de tratar e interiorizar estas aventuras. $\mathrm{O}$ tratamento aqui dado à questão é convergente com o que detetamos na Bíblia.

A incapacidade demonstrada por Hipólito de corresponder à solicitação de amor que lhe fora feita por Fedra poderia ser analisada a partir da falta de interesse pessoal concreto, por um lado, da falta de enquadramento familiar adequado, por outro, ou ainda por razões culturais, comportamentais e religiosas implicadas no horizonte das suas opções pessoais. Na Bíblia, esta temática da recusa de amar não é muito visível. Preferências de amor são explicitadas até de forma exageradamente simplificada, distinguindo como amar e odiar matizes normais de gostar mais de uma das suas mulheres do que da outra $(1 \mathrm{Sm} 1,5)^{6}$. As incapacidades fundadas no parentesco já vimos que são amplamente consideradas. Outras razões para justificar atitudes de encratismo religioso ou cultural não parecem intervir.

Nas literaturas da Mesopotâmia, no entanto, é tradicional e conhecido um tema de recusa de amor e casamento a uma proposta feita pela deusa Inanna e pela sua correspondente semítica Ishtar. Gilgamesh, na respetiva epopeia, é o caso clássico de expressão literária para essa recusa. As razões expressas apontam para o feitio difícil ou para as exigências da deusa que se propõe a si mesma em casamento. É evidente que as reticências relatadas sobre o feitio dessa deusa devem representar intuições de fundo elaboradas na cultura mesopotâmica, relativamente a um caso tão sério de amor como este $^{7}$.

É possível aperceber-se alguma espécie de recusa do amor inoculada nos discursos de crítica ao comportamento das mulheres, facilmente detetáveis nas versões moralistas da sabedoria hebraica tradicional (Pr 5,1-14; Sir 25,13-26; 26,1-12). Mas este discurso frequentemente rigoroso não parece conter nenhuma razão que contradiga o casamento.

\footnotetext{
${ }^{5}$ Vd. M. Lichtheim 1984 II: 203-214 e J. Nunes Carreira 2005: 162-167.

${ }^{6}$ As traduções dirão legitimamente que Elcana amava mais Ana do que Penina. O texto hebraico diz simplesmente que "amava" Ana. Não amar a outra desta maneira cai dentro de semântica do verbo "odiar", por muito que isso não coincida com as nossas fórmulas.

${ }^{7}$ R. Tournay, A. Shafter 1994: 144-150.
} 
Um caso bíblico de impossibilidade de amor por impedimento derivado de cumplicidades religiosas familiares é o caso da filha do juiz Jefté, que, ao sair festivamente para saudar o pai que regressava vitorioso da guerra, toma por ele mesmo conhecimento que o seu próprio pai fizera um voto de oferecer em sacrifício a primeira pessoa que lhe saísse ao caminho (Jz 11,29-40). Ao saber deste voto do pai, a tragédia que de imediato ocorreu à filha de Jefté foi a da sua virgindade confrontada com este destino trágico. Pediu, por isso, ao pai que a deixasse ir fazer o luto com as suas amigas, pelas montanhas, chorando o destino triste da sua virgindade inconclusa. Mais do que uma recusa genérica do amor, temos aqui uma afirmação pessoal inquestionável do mesmo. A impossibilidade não provém de uma opção da própria; é imposição da solidariedade familiar e da mentalidade religiosa ocasional. Esta tragédia abate-se tanto sobre a filha como sobre o pai, pois fica bem sublinhado que este não tem mais filhos nem filhas; é a única.

Subjetivamente esta tragédia é rotulada como desespero e desgraça. Objetivamente, ela é fruto de um excesso de linguagem no voto pronunciado para com Javé. Jefté prometera sacrificar o primeiro que lhe viesse ao encontro, sem pensar que poderia com isso provocar uma desgraça $(\mathrm{Jz} 11,35-36)$. É um caso de autêntica tragédia, onde o vivencial sai claramente a perder na concorrência com o simbólico.

Acontece, entretanto, que a viabilidade histórica de gestos como este se projeta para o fundo de uma época em que poderia haver ainda em Israel sacrifícios humanos em honra de Javé. A historiografia de Israel não comprova esta prática de sacrifícios humanos em época histórica. A ortopráxis de Israel historicamente reconhecida parece não patrocinar estas práticas. Apesar disso, esta tradição aí fica, resistindo incólume na literatura dos hebreus com este e outros indícios (Gn 22,12; Ex 13,11-16; Lv 18,21; 2Rs 3,27; Is 30,33; Jr 7,31-34; 19,3-13; Ez 16,20-22; Mq 6,6-8).

\section{Aporia e tragédia na textura do amor}

Estas complicações do comportamento psicológico e emocional, relativas a momentos concretos da relação amorosa, para além de se poderem considerar peripécias de circunstância, inscrevem-se com alguma naturalidade nas perspetivas bíblicas sobre a essência principal do amor. Elas são descritas na parcela de definição do amor que cabe formular dentro do percurso vivencial específico da mulher $(\mathrm{Gn} 3,16)$. Com efeito, o amor é a mulher ${ }^{8}$. E esta vive, na sua experiência feminina, uma contradição entre a

8 Tratámos desta perspetiva de análise em "A sexualidade entre os hebreus: caminhos essenciais do sentido”, in J. A. Ramos, M. C. Fialho, N. S. Rodrigues 2009: 229, 234. 
atração e a sujeição, sempre por razões de amor para com o seu marido. São os ingredientes do amor, repartidos entre os dois pólos, idealista e realista, da sua dinâmica existencial. Esta dinâmica de vida é para ela tão querida como uma definição e tão inelutável como um castigo $(\mathrm{Gn} 3,16)$. Em Fedra como no conto egípcio, é de novo a mulher a carregar com esta dramática definição de contrastes.

Na verdade, a conceção bíblica sobre a mulher implica alguma polaridade. Por um lado, ela atrai e faz sair o homem do seu reduto e recoloca-o noutro espaço (Gn 2,24), tão unitário que como que deixa de ser um espaço e se torna apenas numa modalidade de existir, "uma só carne". Por outro lado, a mulher pode representar uma força de arrastamento para redutos inóspitos (Pr 7,1-27). A própria dinâmica de sedução integra os mesmos dois pólos: o da cumplicidade transgressiva (Gn 3,12) e o da fusão mística com Deus (Jr $20,7)^{9}$. Uma teologia assente na relação amorosa dá à experiência religiosa dos humanos um cariz feminino. A textualização bíblica desta perspetiva assenta no pensamento dos profetas Oseias, Jeremias e Ezequiel (Os 2,5-25; Jr 2-4; $\mathrm{Ez}$ 16). Os meios complementares da procura podem ser representados por duas figuras femininas em antítese: a da Senhora Sabedoria e a da Senhora Insensatez (Pr 9,1-6.13-18).

É claro que esta variedade de experiências ocorre também conforme as contingências da escolha de um companheiro, com fatores de maior ou menor sorte. As conotações absolutas encontram-se na própria definição de estrutura da relação; os dramas podem ocorrer naturalmente por entre cada um dos múltiplos conflitos individualizáveis.

Fedra deverá igualmente conter aquilo que é do âmbito das definições estruturais, misturado com aquilo que pertence ao domínio das circunstâncias e contingências da experiência individual. A linguagem da tragédia contém a imagem do estrutural, bem como a expressão de toda a existencialidade envolvente e cúmplice da estrutura.

Todas as aporias do humano se repercutem sobre as relações estruturais com que este aparece configurado, como se toda a consistência e sentido da vida dependessem precisamente dessa relação concreta.

Esta leitura constitui uma declaração sobre o valor absoluto da relação de amor. Com ela, tendemos naturalmente a instaurar sobre o outro a estrutura principal do sentido da vida, pendendo para imputar a esse tu o estado geral do nosso mundo. Esta é mais uma utopia, desejável e aporética como todas elas. Mas parece de apetência inquestionável e poderá mesmo ter algum sentido estrutural.

${ }^{9}$ O verbo hebraico utilizado para "seduzir", pth, convoca todos os matizes da sedução. Cf. E. Jenni, C. Westermann 1984 II: 495-497. 
Pode, entretanto, ficar-nos a interrogação, nesta busca da parceria estrutural, para saber se se trata de uma consciência de contingente em busca de uma referência de absoluto ou é já uma consciência de absoluto, procurando validar ou simplesmente exprimir uma estrutura de partilha.

Entretanto, as aporias e contrastes implicados no amor e sexualidade não chegam a formular razões ou comportamentos de encratismo ou recusa do amor como a protagonizada por Hipólito, considerada por si mesma e fora do contexto de conflitualidade familiar em que se processa. $\mathrm{O}$ homem bíblico é sexualmente interessado e sadio; não conhece movimentos de rejeição da sexualidade (apud J. A. Ramos, in J. A. Ramos, M. C. Fialho, N. S. Rodrigues 2009: 223). O próprio encratismo bíblico é sexual na sua dinâmica e nas suas formulações metafóricas (apud J. A. Ramos 2004: 38-39). É feito por amor de uma outra utopia e exprime-se igualmente em categorias passionais e eróticas.

Se, porém, o caso de Hipólito tiver alguma conotação mística de adoração pela deusa Ártemis (apud F. C. Zorrer da Silva 2001: 142 sqq.), em contraposição com o culto sexual a Afrodite, então podemos sugerir uma analogia bíblica, a do encratismo pelo Reino (Mt 19, 10-12). Esta é a única forma teorizada na Bíblia de renúncia ao amor sexual. É justificada por esta opção funcionalmente alternativa, se bem que estruturalmente análoga ao primeiro. Semelhanças mais elaboradas com o caso de Hipólito dirão respeito a outras abordagens.

A tragédia é um momento da consciência humana em estado dialético de aporia. Tais estados sem solução antevista existem certamente na Bíblia, porque eles representam momentos de síntese privilegiada da consciência humana.

Excetuando o caso de Job, o qual aborda de forma aporética o sentido do próprio agir humano, domínio que poderá ser considerado mais profundo ou não, o homem bíblico não desenvolveu a tendência para formular em estados trágicos de consciência a confrontação com as aporias ocorrentes nos diversos domínios da vida, da mesma maneira que o cansaço da vida não desenvolveu nenhuma atitude de apologia para o suicídio. A característica mais marcante do humanismo bíblico é que ele é combativamente demiúrgico. A vida é criação e o sentido é parte integrante disso.

E sabe bem que isto possa reconhecer alguma razão ao grito existencialmente demiúrgico de Sartre. Eventualmente para surpresa dele, mas não é certamente por mal. 